\title{
Study of Convective Heat Transfer through Micro Channels with Different Configurations
}

\author{
D. S. Ghodake ${ }^{* *}$ and Rakesh Siddheshwar ${ }^{\dagger}$ \\ ${ }^{\dagger}$ Mechanical Engineering Department, JSPM’s JSCOE, Hadapsar, Savitribai Phule Pune University, Pune, Maharashtra, India
}

Accepted 02 March 2016, Available online 15 March 2016, Special Issue-4 (March 2016)

\begin{abstract}
The micro channel heat sinks play a very important role in the functioning of the micro-electronic components. In this paper the focus is on the convective heat transfer performance of the micro channels with different geometric configurations. The heat transfer performance is a function of surface area available for the heat transfer and the heat transfer coefficient of the heat carrying medium. An experimental heat transfer analysis is carried out with different configurations of micro channels. Micro channels with four different configurations are fabricated using Photo Chemical Machining Process. The performance analysis is done in the Reynolds Number range of 15 to 50, with different inlet flow velocities and the experimental analysis emphasis the fact that the geometrical configuration of the channel has a considerable effect on the micro channel heat transfer performance and in turn on the performance of the micro-electronic components.
\end{abstract}

Keywords: Convective Heat transfer, Convective Heat Transfer Coefficient, Micro- channel, Nusselts Number, Reynolds Number.

\section{Introduction}

Size reduction is the buzzword in the modern electronic industry. But with the reduction in component size, different new problems like heat dissipation becomes critical and sometimes these devices fails due to overheating. Therefore it is very much important to dissipate the heat developed by such small equipments with faster rate or within very short span of time. The most promising solution for this problem is the introduction of micro or mini channels into the heat sinks. The main purpose of introducing micro- channel or mini channel is to increase the surface area which is exposed for heat transfer.

Numerous works have been reported relating to heat transfer as well as pressure drop with different geometrical configurations. However there still a lot of scope remaining for research on heat transfer \& pressure drop in the micro- channel. The main objective of this paper is to study the convective heat transfer in micro- channel and also the effects of various parameters such as Reynolds number, inlet velocity of cooling fluid and rise in temperature of cold fluid. This paper mainly focuses on heat transfer through different configurations of micro- channels such as straight, square, triangular, circular and the comparison between them.

Naphon et al. (2009) studied the convective heat transfer \& pressure drop in the micro- channel heat

*Corresponding author: D. S. Ghodake sink. Kayehpour et al. (1997) studied the effects of compressibility and rarefaction on the gas flows in micro-channels. Chen (1998) numerically analyzed the flow characteristics in micro-channels. Ambatirudi et al. (2000) analyzed the heat transfer in micro-channel heat sinks. Ng and Poh (2001) applied the CFD for analysis of liquid flow in the double layer microchannel. Zhao and Lu (2002) presented the analytical and numerical study effect of porosity on the thermal performance a micro-channel heat sink. Xuan (2003) investigated the effect of the thermal and contact resistances of ceramic plate in thermoelectric microcoolers. Hao and Tao (2004) applied a numerical model to analyze the phase-change flow in micro-channels Bhowmil (2005) studied on the steady-state convective heat transfer of water from an in-line four electronic chips in a vertical rectangular channel. Zhang et al. (2005) reported the study of a single-phase heat transfer of micro-channel heat sink for electronic packages. Didarul (2007) investigated the heat transfer and fluid flow characteristics of finned surfaces. Zhen et al. (2007) compared the 3-D and 2-D DSMC heat transfer of flow-speed short micro-channel flows. Wang et al. (2008) numerically studied the gas flow and heat transfer in a micro-channel using DSMC with uniform heat flux boundary condition.

\section{Experimental Apparatus}

The experimental setup consists of mainly three parts which are heater assembly, temperature measuring unit, and different geometries of micro- channels. 


\section{A. Heater assembly}

The heater assembly is as shown in fig.1. For the preparation of heater assembly, initially a wooden block is taken of dimension $130 * 70 \mathrm{~mm}$ as a base. On this wooden base asbestos sheet of $130 * 70$ is placed as insulating material. Now on this asbestos sheet heating coil with Mica sheet is placed and finally over this surface Aluminum sheet of thickness $0.5 \mathrm{~mm}$ is placed for uniform heating.

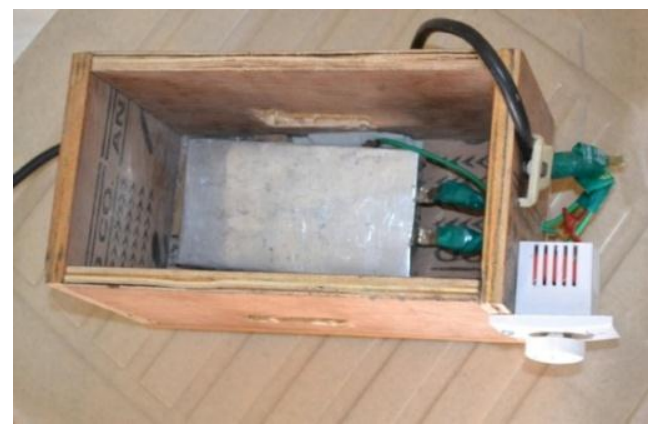

Fig.2.1 Heater Assembly

\section{B. Temperature Measuring Unit}

This unit is used for measuring inlet \& outlet temperature of water to and from the micro channel heat sink. It consists of electronic components like LM35 (Integrated Circuit Temperature Sensor), Microcontroller Board, Potentiometer.

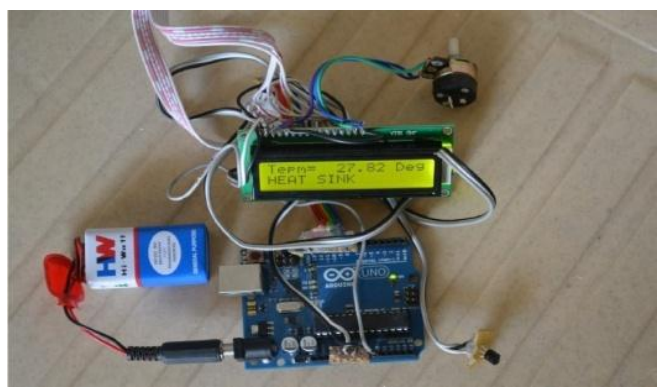

Fig.2.2 Temperature Measuring Unit

Different Geometries of Micro- Channels are used in this study. For the preparation of these different configurations of micro- channel, Copper is selected as raw material due to its higher heat transfer capability.

To study the heat transfer through micro- channels. Following types of micro channel Configurations are selected rectangular, Square, Triangular and Circular. For manufacturing of these configurations a nonconventional machining process such as Photo Chemical Machining is used. After preparation of different configurations of micro- channels they are placed on the heater element and to avoid leakage between the test plate $\&$ heater element Teflon coating is provided on the channel. An AC supply is power source for heaters. The rear side of heater is insulated with a thick Mica resistant sheet followed by acrylic sheet \& wooden plate. The LM35 thermocouples are used to measure the temperate of inlet \& outlet water to and from the micro- channel.

\section{Design of Micro Channels}

\section{Design Process}

\section{A. Selection of Geometries}

The following geometries are selected,

- Rectangular

- Square

- Triangular

- Circular

\section{B. Designing of geometries}

All geometries are designed by keeping surface area and depth of micro channel as constant.

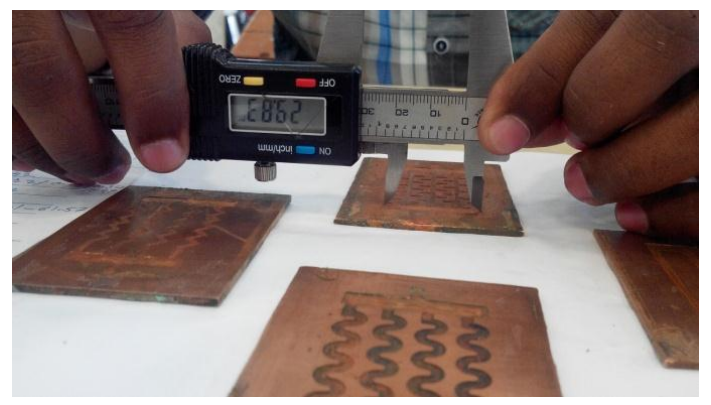

Fig.3.1 Design of Micro Channel

\section{Preparation of AutoCAD Drawing}

In order to design the different geometrical configurations micro channel heat sink very careful approach has to be adopted. By using AutoCAD 2015 CAD drawings are prepared for different configurations of micro channels.

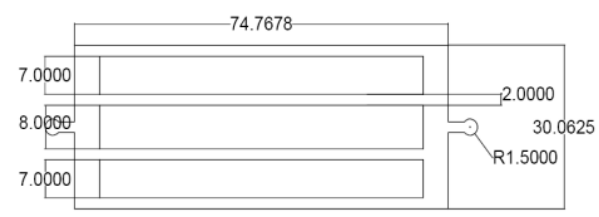

Fig.3.2 Rectangular Micro Channel

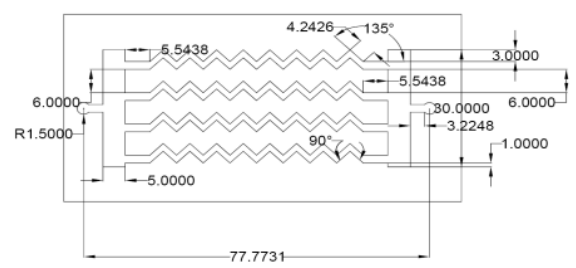

Fig.3.3 Triangular Pattern Micro Channel 


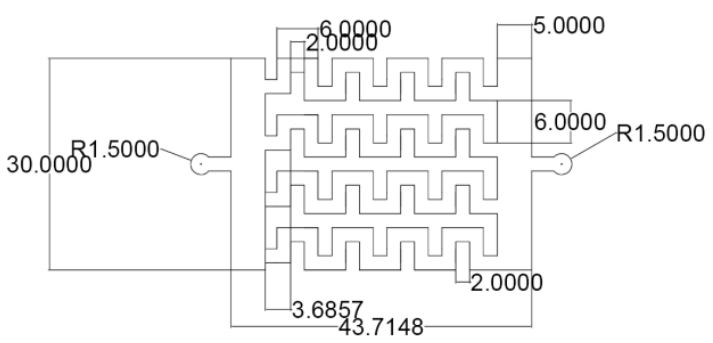

Fig.3.4 Square Pattern Micro Channel

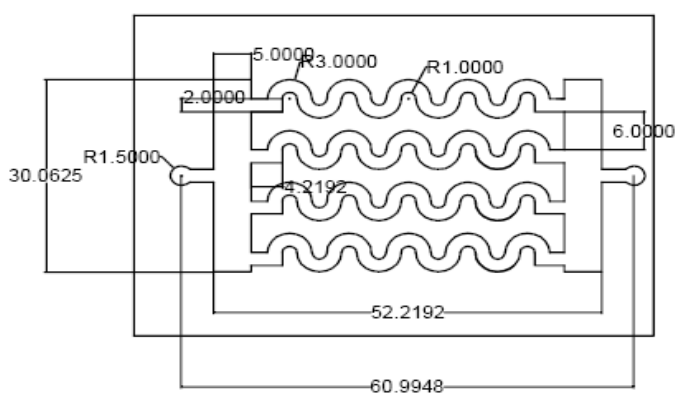

Fig.3.5 Circular Pattern Micro Channel

\section{Selection of cold fluid}

To find the heat transfer rate through different geometrical configurations of micro channels water is considered as cooling fluid.

\section{E. Selection of Raw Material}

The Copper is selected as a raw material by considering following properties,

- Melting temperature: $1084.62^{\circ} \mathrm{C}$

- Thermal conductivity: $401 \mathrm{~W} / \mathrm{m} . \mathrm{K}$

- Electric resistivity: $16.78 \mathrm{n} \Omega \cdot \mathrm{m}\left(20^{\circ} \mathrm{C}\right)$

- Size: $50 \mathrm{~mm}^{*} 70 \mathrm{~mm}$

Channel width: $2 \mathrm{~mm}$

Channel height: $500 \mu \mathrm{m}$

\section{Calculations}

The Heat transferred to the cooling water in the test section, $\mathrm{Q}_{\mathrm{w}}$, is given by,

$\mathrm{Q}_{\mathrm{w}}=\mathrm{m}_{\mathrm{w}} C \mathrm{p}_{\mathrm{w}}\left[\left(\mathrm{T}_{\mathrm{w}, \text { ave }}\right)_{\text {out }}-\left(\mathrm{T}_{\mathrm{w}, \mathrm{ave}}\right)_{\mathrm{in}}\right]$

Where,

$\mathrm{m}_{\mathrm{w}}=$ Mass flow rate of water $(\mathrm{Kg} / \mathrm{Sec}$. $)$

$\mathrm{Cp}_{\mathrm{w}}=$ Specific heat capacity of water $(\mathrm{kJ} / \mathrm{KgK})$

$\left(\mathrm{T}_{\mathrm{w}, \text { ave }}\right)_{\text {out }} \&\left(\mathrm{~T}_{\mathrm{w}, \text { ave }}\right)_{\text {in }}$ are the average outlet and inlet water temperatures respectively.

Heat added to the micro-channel is given by,
$\mathrm{Q}_{\text {heater }}=\mathrm{V}^{*} \mathrm{I}$

The average heat transfer rate, $Q_{\text {avg, }}$ used in the calculation is determined from the heat transferred to the cooling water and the heat supplied to the heat source as follows:

$\mathrm{Q}_{\mathrm{avg}}=\left[\left(\mathrm{Q}_{\mathrm{w}}+\mathrm{Q}_{\text {heater }}\right) / 2\right]$

The average heat transfer coefficient can be calculated from

$\mathrm{Q}_{\mathrm{avg}}=\mathrm{h}_{\mathrm{m}} \cdot \mathrm{A}_{\mathrm{m}}\left(\Delta \mathrm{T}_{\mathrm{LMTD}}\right)$

Where,

$\Delta \mathrm{T}_{\mathrm{LMTD}}=\frac{[\mathrm{Ts}, \text { avg }-(\mathrm{Tw}, \mathrm{avg}) \mathrm{in}]-[\mathrm{Ts}, \mathrm{avg}-(\mathrm{Tw}, \mathrm{avg}) \text { out }]}{\ln \frac{[\mathrm{Ts}, \text { avg-(Tw,avg)in }]}{[\mathrm{Ts}, \text { avg }-(\mathrm{Tw}, \text { avg }) \text { out }]}}$

Where,

$\mathrm{T}_{\mathrm{s}, \text { avg }}=$ average surface temperature $\left({ }^{\circ} \mathrm{C}\right)$

$\mathrm{A}_{\mathrm{m}}=$ surface area of the micro-channel $\left(\mathrm{mm}^{2}\right)$

The average heat transfer coefficient is presented in terms of average Nusselts Number as given bellow,

$\mathrm{Nu}=\frac{\mathrm{hmDh}}{\mathrm{K}}$

Where,

$\mathrm{K}=$ Thermal Conductivity of water $(\mathrm{W} / \mathrm{mK})$

$\mathrm{D}_{\mathrm{h}}=$ Hydraulic diameter of channel $(\mathrm{mm})$

The Reynolds number based on $\mathrm{D}_{\mathrm{h}}$ of micro- channel is,

$\operatorname{Re}=u D_{h} / v$

Where,

$\mathrm{D}_{\mathrm{h}}=\frac{4 \text { Acs }}{\mathrm{P}}$

Where,

$\mathrm{u}=$ Water velocity $(\mathrm{m} / \mathrm{s})$

$v=$ Kinematic viscosity $\left(\mathrm{m}^{2} / \mathrm{s}\right)$

$\mathrm{A}_{\mathrm{cs}}=$ Cross sectional area of micro- channel $\left(\mathrm{mm}^{2}\right)$

$\mathrm{P}=$ Wetted perimeter $(\mathrm{mm})$

\section{Results and Discussions}

\subsection{Analysis of Square Micro Channel}

Table 5.1 Results of Square Micro Channel

\begin{tabular}{|c|c|c|c|}
\hline Sr. No & h (Experimental) & h (Theoretical) & $\begin{array}{c}\mathbf{\%} \\
\text { Deviation }\end{array}$ \\
\hline 1. & 823.4722 & 1204.058 & 31.60 \\
\hline $\mathbf{2 .}$ & 982.2247 & 1379.240 & 28.78 \\
\hline $\mathbf{3 .}$ & 1048.513 & 1516.991 & 30.88 \\
\hline $\mathbf{4 .}$ & 1144.463 & 1633.725 & 29.94 \\
\hline
\end{tabular}

From Fig. 5.1 it is clear that the value of heat transfer coefficient goes on increasing with increase in the 
value of Reynolds Number. There is around $30 \%$ deviation of experimental value of heat transfer coefficient from theoretical value.

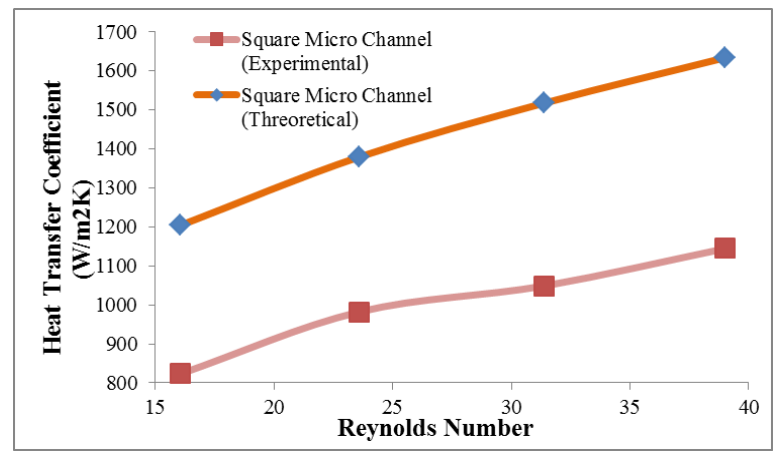

Fig.5.1 Variation of Heat Transfer Coefficient w. r. t. Reynolds Number

\subsection{Analysis of Rectangular Micro Channel}

Table 5.2 Results of Rectangular Micro Channel

\begin{tabular}{|c|c|c|c|}
\hline Sr. No. & $\begin{array}{c}\mathbf{h} \\
\text { (Experimental) }\end{array}$ & h (Theoretical) & $\begin{array}{c}\text { \% } \\
\text { Deviation }\end{array}$ \\
\hline $\mathbf{1 .}$ & 843.764829 & 1040.4330 & 18.902 \\
\hline $\mathbf{2 .}$ & 1041.16070 & 1193.16963 & 12.739 \\
\hline $\mathbf{3 .}$ & 1210.12729 & 1432.91467 & 15.547 \\
\hline $\mathbf{4 .}$ & 1510.45123 & 1545.55959 & 2.2715 \\
\hline
\end{tabular}

From Fig.5.2 it is clear that the value of heat transfer coefficient goes on increasing with increase in the value of Reynolds Number. There is around $12 \%$ deviation of experimental value of heat transfer coefficient from theoretical value.

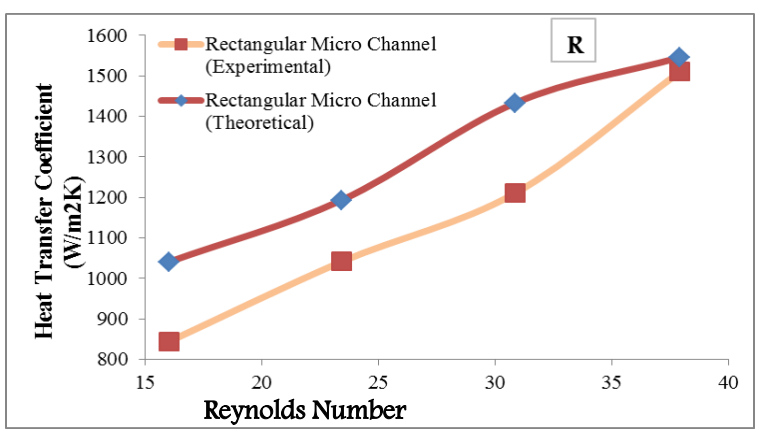

Fig. 5.2 Variation of Heat Transfer Coefficient w. r. t. Reynolds Number

\subsection{Analysis of Triangular Micro Channel}

Table 5.3 Results of Triangular Micro Channel

\begin{tabular}{|c|c|c|c|}
\hline Sr. No. & $\begin{array}{c}\mathbf{h} \\
\text { (Experimental) }\end{array}$ & $\begin{array}{c}\mathbf{h} \\
\text { (Theoretical) }\end{array}$ & \% Deviation \\
\hline $\mathbf{1 .}$ & 1084.78137 & 1625.29 & 33.256371 \\
\hline $\mathbf{2 .}$ & 1235.98571 & 1858.00 & 33.477945 \\
\hline $\mathbf{3 .}$ & 1488.19582 & 2045.49 & 27.245112 \\
\hline $\mathbf{4 .}$ & 1748.91678 & 2202.65 & 20.599440 \\
\hline
\end{tabular}

From Fig.5.3 it is clear that the value of heat transfer coefficient goes on increasing with increase in the value of Reynolds Number. There is around $28 \%$ deviation of experimental value of heat transfer coefficient from theoretical value.

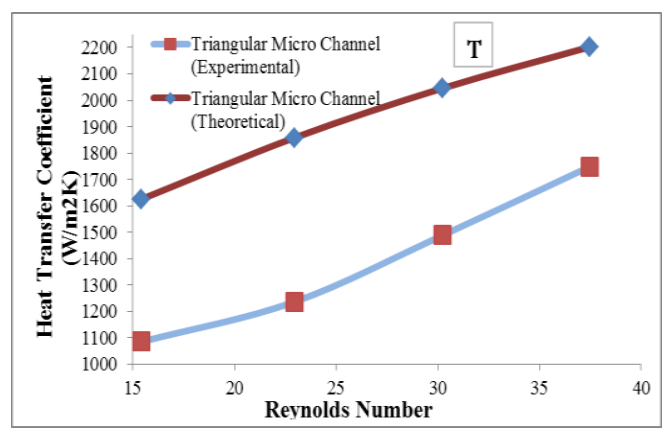

Fig.5.3 Variation of Heat Transfer Coefficient w. r. t. Reynolds Number

\subsection{Analysis of Circular Micro Channel}

Table 4.4 Results of Circular Micro Channel

\begin{tabular}{|c|c|c|c|}
\hline Sr. No. & $\begin{array}{c}\mathbf{h} \\
\text { (Experimental) }\end{array}$ & $\begin{array}{c}\mathbf{h} \\
\text { (Theoretical) }\end{array}$ & \% Deviation \\
\hline $\mathbf{1 .}$ & 857.985545 & 1136.218331 & 24.487616 \\
\hline $\mathbf{2 .}$ & 1029.23657 & 1301.45404 & 20.916410 \\
\hline $\mathbf{3 .}$ & 1211.94639 & 1292.465245 & 6.2298660 \\
\hline $\mathbf{4 .}$ & 1380.67179 & 1414.991331 & 2.4254238 \\
\hline
\end{tabular}

From Fig.5.4 it is clear that the value of heat transfer coefficient goes on increasing with increase in the value of Reynolds Number. There is around $14 \%$ deviation of experimental value of heat transfer coefficient from theoretical value.

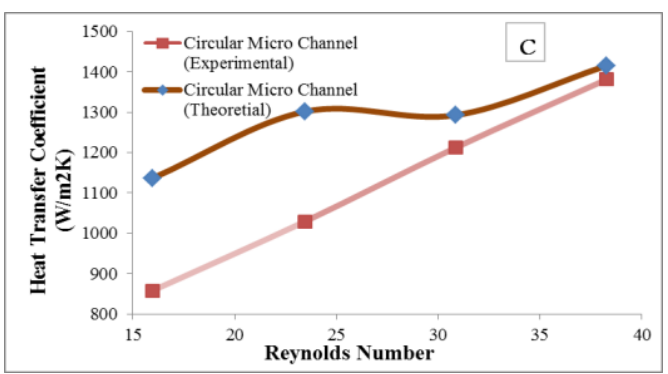

Fig.5.4 Variation of Heat Transfer Coefficient w. r. t. Reynolds Number

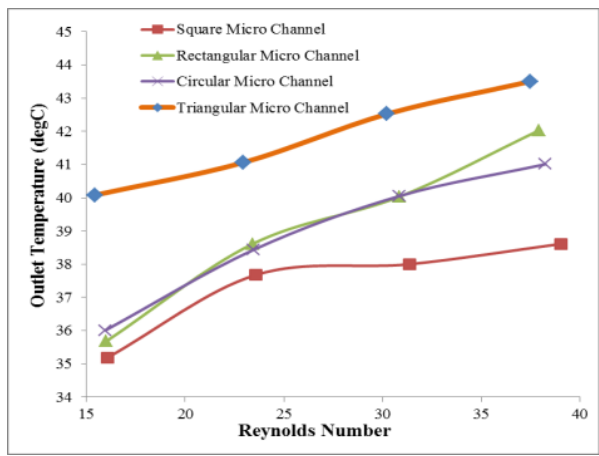

Fig.5.5 Outlet Temperature of Cooling Fluid Vs Reynolds Number 
Fig.5.6 shows variation of experimental value of heat transfer coefficient with respect to Reynolds Number. Here also for triangular geometry the experimental value of heat transfer coefficient is higher as compared with remaining three geometries. For triangular geometry the value of heat transfer coefficient is 50 $55 \%$ more than square geometry, 15 - $20 \%$ more than rectangular and 25 - $30 \%$ more than circular geometry.

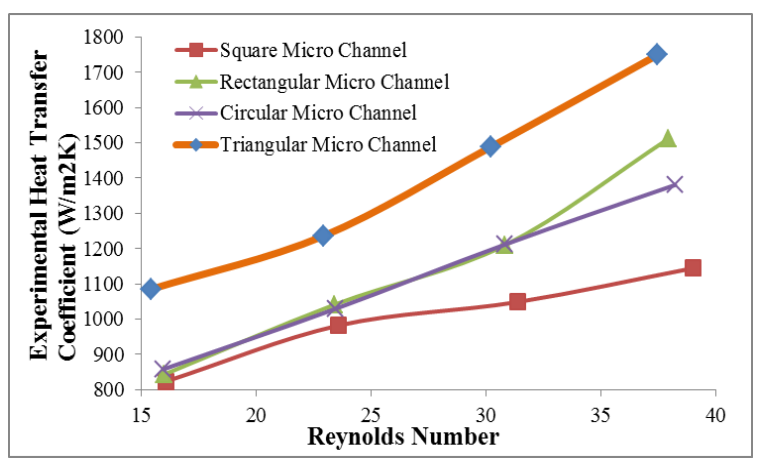

Fig.5.6 Experimental Heat Transfer Coefficient Vs Reynolds Number

Fig.5.7 shows variation of experimental value of heat transfer coefficient with respect to Reynolds Number. For triangular geometry the experimental value of Nusselts Number is higher as compared with rest three geometries. For triangular geometry the value of Nusselts Number is 40 - $45 \%$ more than square geometry, 15 - $20 \%$ more than rectangular and 25 $30 \%$ more than circular geometry.

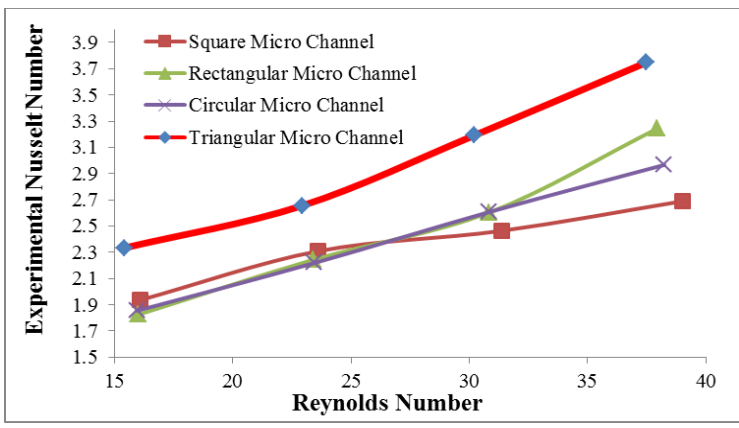

Fig.5.7 Experimental Nusselts Number Vs Reynolds Number

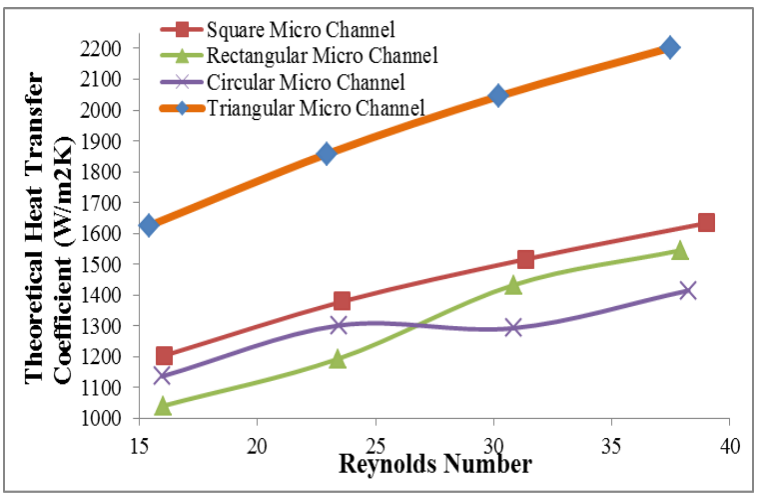

Fig.5.8 Theoretical Heat Transfer Coefficient Vs Reynolds Number
Fig. 4.8 shows the variation of theoretical value of heat transfer coefficient with respect to Reynolds Number. For triangular geometry the theoretical value of heat transfer coefficient is higher as compared with rest three geometries. For triangular geometry the value of heat transfer coefficient is $30-35 \%$ more than square geometry, 40 - $45 \%$ more than rectangular and 50 $55 \%$ more than circular geometry.

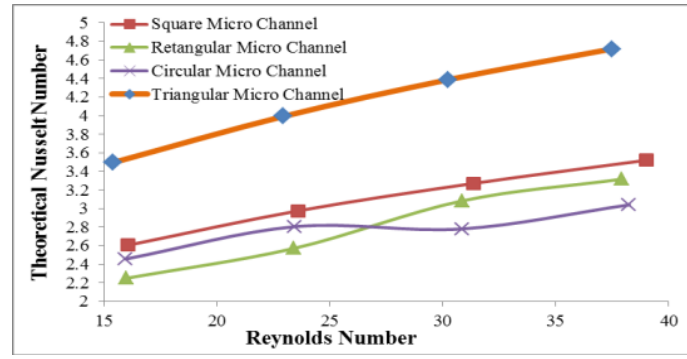

Fig.5.9 Theoretical Nusselts Number Vs Reynolds Number

Fig.5.9 shows the variation of theoretical value of Nusselts Number with respect to Reynolds Number. For triangular geometry the theoretical value of Nusselts Number is higher as compared with rest three geometries. For triangular geometry the value of Nusselts Number is $30-35 \%$ more than square geometry, $40-45 \%$ more than rectangular and 50 $55 \%$ more than circular geometry.

5.5 Deviation of Experimental Heat Transfer Coefficient from Theoretical Value

Table 5.5 Deviation of Experimental Heat Transfer Coefficient from Theoretical Value

\begin{tabular}{|c|c|c|}
\hline \multicolumn{3}{|c|}{ Square Micro Channel } \\
\hline $\begin{array}{c}\text { h }(\mathrm{W} / \mathrm{m} 2 \mathrm{~K}) \\
\text { (Experimental) }\end{array}$ & $\begin{array}{c}\text { h }(\mathrm{W} / \mathrm{m} 2 \mathrm{~K}) \\
\text { (Theoretical) }\end{array}$ & \% Deviation \\
\hline 823.4722994 & 1204.05803 & 31.60858703 \\
\hline 982.2247447 & 1379.240787 & 28.78511469 \\
\hline 1048.513128 & 1516.991344 & 30.88206253 \\
\hline 1144.463988 & 1633.725639 & 29.94760193 \\
\hline \multicolumn{3}{|c|}{ Rectangular Micro Channel } \\
\hline $\begin{array}{c}\mathrm{h}(\mathrm{W} / \mathrm{m} 2 \mathrm{~K}) \\
\text { (Experimental) }\end{array}$ & $\begin{array}{c}\text { h }(\mathrm{W} / \mathrm{m} 2 \mathrm{~K}) \\
\text { (Theoretical) }\end{array}$ & \% Deviation \\
\hline 843.764829 & 1040.433005 & 18.90253148 \\
\hline 1041.160706 & 1193.169632 & 12.73992577 \\
\hline 1210.127293 & 1432.914675 & 15.54784705 \\
\hline 1510.451233 & 1545.559599 & 2.271563355 \\
\hline \multicolumn{3}{|c|}{ Circular Micro Channel } \\
\hline $\begin{array}{c}\mathrm{h}(\mathrm{W} / \mathrm{m} 2 \mathrm{~K}) \\
\text { (Experimental) }\end{array}$ & $\begin{array}{c}\text { h }(\mathrm{W} / \mathrm{m} 2 \mathrm{~K}) \\
\text { (Theoretical) }\end{array}$ & \% Deviation \\
\hline 857.9855451 & 1136.218331 & 24.48761634 \\
\hline 1029.236571 & 1301.45404 & 20.91641044 \\
\hline 1211.946391 & 1292.465245 & 6.229866056 \\
\hline 1380.671793 & 1414.991331 & 2.425423877 \\
\hline \multicolumn{3}{|c|}{ Triangular Micro Channel } \\
\hline $\begin{array}{c}\mathrm{h}(\mathrm{W} / \mathrm{m} 2 \mathrm{~K}) \\
\text { (Experimental) }\end{array}$ & $\begin{array}{c}\text { h (W/m2K) } \\
\text { (Theoretical) }\end{array}$ & \% Deviation \\
\hline 1084.781379 & 1625.295793 & 33.25637191 \\
\hline 1235.985717 & 1858.008944 & 33.47794577 \\
\hline 1488.195824 & 2045.49257 & 27.24511219 \\
\hline 1748.916787 & 2202.650449 & 20.59944019 \\
\hline
\end{tabular}

5| MIT College of Engineering, Pune, India, AMET 2016, INPRESSCO IJCET Special Issue-4 (March 2016) 
From above graphs it is clear that for every geometrical configuration

1. With increase in outlet temperature of water there is increase in Nusselts number in turn increase in heat transfer.

2. With decrease in surface temperature of heat sink there is increase in Nusselts number in turn increase in heat transfer.

3. With increase in heat transfer coefficient of water there is increase in Nusselts number in turn increase in heat transfer.

4. As temperature rise of cooling water in case of triangular micro channel is much higher as compared with rest three configurations.

5. The increase in heat transfer coefficient of cooling water in triangular micro channel is around 15 $20 \%$ more than rectangular micro channel, 25 $30 \%$ more than circular micro channel and 50 $55 \%$ more than square micro channel. As the value of heat transfer coefficient is more in triangular micro channel therefore, it is concluded that the triangular geometrical configuration is best suited to have higher heat transfer through the micro channel.

\section{Conclusions}

Different geometrical configuration of copper micro channels is analyzed for their heat transfer performance in this work. The results show that the geometrical configuration of the micro channel affects the heat transfer performance of the micro channel heat sink to a considerable extent. Comparatively the triangular configuration resulted in giving better performance when compared to other types used in this experimentation.

\section{Acknowledgements}

I am thankful to my guide Prof. Rakesh Sidhheshwar for his guidance and being source of motivation to complete the work. I am also thankful to Prof. B. P. Ronge, Principal, SVERI's COE, Pandharpur, Prof. P. M. Pawar, Dean (R \& D), SVERI's COE, Pandharpur, Prof. N. D. Misal, Principal, SVERI's COE (POLY), Pandharpur for providing all facilities without which this work would not have been possible. I am thankful to my Micro- fluidics LAB Team for their technical help and suggestions.

\section{References}

P. Naphon et al. (2009), Study on the convective heat transfer and pressure drop in the micro-channel heat sink", International Communications in Heat and Mass Transfer, 36, 39- 44.

H. P. Kayehpour et al, Effects of compressibility and rarefaction on gaseous flows in micro-channel", Numerical Heat Transfer, 32 (1997) 677-69.
C. S. Chen (1998), Numerical analysis of gas flow in Micro channels, Numerical Heat Transfer, 33, 749-762.

K. H. Ambatirudi et al. (2000), Analysis of conjugate heat transfer in micro channel heat sinks, Numerical Heat Transfer, 37, 711-731.

E. Y. K. Ng et al. (2001), CFD analysis of double- layer micro channel conjugate parallel liquid flows with electric double-layer effects, Numerical Heat Transfer, 40, 735749.

C. Y. Zhao et al. (2002), Analysis of micro channel heat sink for electronics cooling, International Journal of Heat and Mass Transfer, 45, 4857-4869.

X. C. Xuan (2003), Investigation of thermal contact effect on thermoelectric coolers, Energy Conservation and Management, 44, 399-410.

Y. L. Hao et al. (2004), A numerical model for phase-change suspension flow in micro-Channels, Numerical Heat Transfer, 46, 55-77.

H. Bhowmil (2005), Convection heat transfer from discrete heat sourced in a liquid cooled rectangular channel, Applied Thermal Engineering, 25, 2532-2542.

H. Y. Zhang (2005), Single-phase liquid cooled micro channel heat sink for electronic packages, Applied Thermal Engineering, 25, 1472-1487.

I. M. Didarul (2007), Study on heat transfer and fluid flow characteristics with short rectangular plate fin of different pattern, Experimental Thermal and Fluid Science, 31, 367379.

C. E. Zhen et al. (2007), Comparison of 3-D and 2-D DSMC heat transfer calculations of flow-speed short micro channel flows, Numerical Heat Transfer, 52, 239-250.

Q. W. Wang et al. (2008), Numerical investigation of rarefied diatomic gas flow and heat transfer in a micro channel using DSMC with uniform heat flux boundary conditionPart I: numerical method and Validation, Numerical Heat Transfer, 53, 160-173.

Q. W. Wang et al. (2008), Numerical investigation of rarefied diatomic gas flow and heat transfer in a micro channel using DSMC with uniform heat flux boundary conditionPart II: applications, Numerical Heat Transfer, 53, 174187.

$\begin{array}{ll}\text { Nomenclature } \\ \mathrm{A} & \text { Area }(\mathrm{m} 2) \\ \mathrm{Cp} & \text { Specific Heat, }(\mathrm{kJ} / \mathrm{kgK}) \\ \mathrm{Dh} & \text { Hydraulic Diameter, }(\mathrm{m}) \\ \mathrm{h} & \text { Heat Transfer Coefficient, }\left(\mathrm{kW} / \mathrm{m}^{2} \mathrm{~K}\right) \\ \mathrm{k} & \text { Thermal Conductivity, }(\mathrm{W} / \mathrm{mK}) \\ \mathrm{m} & \text { Mass Flow Rate, }(\mathrm{kg} / \mathrm{s}) \\ \mathrm{Nu} & \text { Nusselts Number } \\ \Delta \mathrm{P} & \text { Pressure Drop, }(\mathrm{kPa}) \\ \mathrm{Pr} & \text { Prandtl Number } \\ \mathrm{P} & \text { Wet Perimeter, }(\mathrm{m}) \\ \mathrm{Q} & \text { Heat Transfer Rate, }(\mathrm{W}) \\ \mathrm{Re} & \text { Reynolds Number } \\ \mathrm{T} & \text { Temperature, }\left({ }^{\circ} \mathrm{C}\right) \\ \mathrm{u} & \text { Velocity, }(\mathrm{m} / \mathrm{s}) \\ \rho & \text { Density, }\left(\mathrm{kg} / \mathrm{m}^{3}\right) \\ \mathrm{w} & \text { Water }\end{array}$

\section{Subscripts}

$\begin{array}{ll}\text { avg } & \text { Average } \\ \text { in } & \text { Inlet } \\ \text { out } & \text { Outlet }\end{array}$

